\title{
Experiencia de Sepsis a Klebsiella en el Servicio de Pediatría del Hospital "Dr. Juan Noé C."
}

\author{
Drs. Milton González A., Enzo Pandolfi B., Jorge Awad R., Rigoberto Mamani M., Amelia del Villar M.* \\ Srtas. Celia Alanoca Araya, Editha Sánchez ${ }^{* *}$, Brunilda Araya***
}

\begin{abstract}
Thirty five patients with Klebsiella Pneumonie Sepsis, from November 1978 to October 1979 oceurred at the Pediatric Department of the Hospital D. Juan Noé C. A ris.a, were analized.

There were 23 infunts 1 month or older and 12 Preterm Newbom. Infints.

Between the infants $52 \%$ were less than 6 months. Stxty five per cent of them were malnourished. Fifty per cent of the Preterm Newborn InFants had Premature Pupture of Membranes, and forty one patient came from distocia labor.

Therapeutic trials with antibiotic association: Cefalotina and Cotrimexazol or Cefalotina and Aunikacine were analized.

The overall mortality was $50 \%$ in Preterm Newbon Infant and $2.7 \%$ in intants 1 month or older.
\end{abstract}

Entre las infecciones intrahospitalarias en neonatos y lactantes predominan en nuestro medio, aquellas provocadas por bacterias Gram negativas, destacando por su frecuencia y gravedad la Sepsis a Klebsiella. ${ }^{1,3}$

Este tipo de infecciones bacterianas, cada vez son más difíciles de tratar, por la resistencia creciente a los antibacterianos conocidos ${ }^{4}$ y porque para prevenirlas se requiere una vigilancia epidemiológica permanente que no siempre es posible reálizar.

* Medicos Servicio Pediatra Hosp. Dr. Juan Noe C.

* Enfermeras Senvicio Pediatría Hosp. Dr. Juan Noe C.

***Tecnólogo Médico Lahoraturio Hosp. Dr. Juan Noé C.
En nuestro Servicio de Pediatria, entre Nov. 78 y Oct. 79 , se presentaron dos brotes epidémicos de Sepsis a Klebsiella, los cuales no ocurrieron simultáneamente. El primero de 23 casos, tue en la Unidad de Lactantes entre Nov, 78 y Ene. 79 y el segundo de 12 casos, en la Unidad de F.N. y Prematuros entre Feb. y Mar. 1979. Esto motivo el estudio y análisis de la situación planteada a fin de:

I. Mostrar la experiencia en Sepsis a Klebsiell a en un Hospital tipo A, alejado del centro del país, comparándola con situaciones semejantes ocurridas en otros centros asistenciales.

II. Analizar las posibles causas relacionadas con el aumento de frecuenciat de esta infección 
intrahospitalaria, a fin de prevenir la aparición de nuevos casos.

\section{MATERIAL Y METODO}

Se revisaron las fichas Clínicas de los pacientes portadores de Sepsis a Klebsiella, confirmados por Hemocultivos +, entre Nov. 78 y Oct. 79 del Servicio de Pediatria de nuestro hospital.

A todos los pacientes se les practica, al ingreso, Hemocultivos, Coprocultivo, Urocultivo, Cultivo y Citoquímico de L.C.R., N. Ureico, Rx. de tórax, cultivos de secreciones cuando se presentan y Hemograma. Los hemocultivos se sembra. ron en medio de Brain-Heart infussion con citrato de Na al 1\%, luego se realizan las pruebas bioquimicas correspondientes a diagnostico de Gram $(-)$; el diagnóstico de especie fue realizado por el Instituto Bacteriológico de Chile.

Los antibiogramas se realizaron por el método de Kirby y Bawer y por el método de dilución para obtener la C.I.M.

Se analizan en forma separada lactantes $y$ R.N. Corresponden a lactantes 23 casos, en que se investiga edad, sexo, est. nutritivo, dg. de ingreso, demora en el dg., cuadro clfíco, exs. de laboratorio, tratamiento y complicaciones. A.R.N. corresponden 12 casos en que se considera edad gestacional, peso de nacimiento, antecedentes de embarazo y parto, dg. de ingreso, demora en el dg., cuadro clínico, exs. de laboratorio, tratamiento y complicaciones.

El estado nutritivo, en lactantes, se clasifican segín Tablas de Sempé; en R.N. el cálculo de edad gestacional se realiza según Tablas de la Dra. Lubchenko.

\section{RESULTADOS}

\section{Grupo A: Lactantes}

Todos los lactantes proceden del área urbana.

La distribución por edad aparece en la Tabla I, apreciándose un claro predominio de los lactantes menores de 6 meses ( $52 \%$ ).

\section{Tabla 1}

Distribución por edad

\begin{tabular}{ccc}
\hline Edad & N. & $\%$ \\
\hline $0-6$ meses & 12 & 52 \\
$7-12$ meses & 7 & 30 \\
$13-24$ meses & 4 & 17 \\
\hline
\end{tabular}

Respecto del estado nutritivo el $65 \%$ tiene algún grado de déticit nutricional predominando el grupo de desnutridos moderados y graves, 47.8\%. (Ver Tabla 2.)

Tabla 2

Distribución de estado nutritivo

\begin{tabular}{lrr}
\hline & N. & $\%$ \\
\hline Eutroficos & 8 & 34,7 \\
D. 1 & 4 & 17,3 \\
D. 2 y D. 3 & 11 & 47,8 \\
\hline
\end{tabular}

En su mayoria los pacientes ingresan por cuadro de neumopatía aguda $(69,5 \%)$ y en menor proporción por diarrea ag. (26\%) I.T.U. $(4,3 \%)$.

La demora diagnóstica fue en promedio de 10,7 días, con un rango de 3-27 días. (Ver Tabla 3.)

Llamamos demora $\mathrm{dg}$, al lapso de tiempo transcurrido hasta la confirmación bacteriologica.

Tabla 3

\section{Demora diagnóstica}

\begin{tabular}{lcr}
\hline Días & $\begin{array}{c}\text { N. }{ }^{\circ} \mathrm{de} \\
\text { casos }\end{array}$ & $\%$ \\
\hline $0-3$ & 2 & 8,6 \\
$4-7$ & 8 & 34,7 \\
$8-14$ & 8 & 34,7 \\
+ de 15 & 5 & 21,7 \\
\hline
\end{tabular}

Dentro de las manifestaciones clínicas encontradas en nuestros pacientes, destacamos en orden de frecuencia el C.E.G. y Fiebre en un $100 \%$, Hepatoesplenomegalia 73,9\%, Tos, quejido y dificultad respiratoria $69,5 \%$. (Ver Tabla 4.)

Entre los exámenes de laboratorio de mayor utilidad en el dg. destacan el Hemograma y los cultivos. En el primero encontramos con mayor frecuencia leucocitosis con desviación izquierda $(69,5 \%)$ y con la misma frecuencia Anemia HemoÍtica, siendo algo menos constante la trombopenia $(56,5 \%)$. En cuanto a los cultivos, como ya se mencionó, el $100 \%$ de los casos presenta uno o más Hemocultivos $(+)$, siendo menos frecuente el hallazgo de coprocultivo (+) $13 \%$ y Urocultivo (+) 4,3\%. Destaor que en todos los pacientes los cultivos de L.C.R. son (-).

Los esquemas terapéuticos iniciales variaron 
Tabla 4

\begin{tabular}{lcc}
$\begin{array}{l}\text { Síntomas y signos en lactantes } \\
\text { con Sepsis a Klebsiella }\end{array}$ & $\begin{array}{c}\text { N. }{ }^{0} \text { de } \\
\text { casos }\end{array}$ & $\%$ \\
\hline Compromiso del estado general & 23 & 100 \\
Fiebre & 23 & 100 \\
Hepatoesplenomegalia & 17 & 73,9 \\
Tos, quejido y dificult. respirat. & 16 & 69,5 \\
Palidez terrosa & 11 & 47,8 \\
Diarrea & 10 & 43,4 \\
Deshidratación & 6 & 26 \\
Vómitos & 3 & 13 \\
Edema & 2 & 8,6 \\
Petequias & 2 & 8,6 \\
Distensión Abdominal & 1 & 4,3 \\
\hline
\end{tabular}

según la edad, diagnóstico de ingreso y antibioticoterapia previa, destacando que en 6 casos $(26 \%)$, se utilizan los esquemas 1 y 2 como tratamiento inicial, dado el cuadro clínico compatible y el antecedente epidemiológico, previa toma de Hemocultivos. En el resto de los casos se utilizan los otros esquemas ${ }^{3,4,5}$ aegún los criterios anteriormente expuestos. Posteriormente es necesarío modificar el esquerna antibiótico en estos 17 casos, a Cefalotina sódica y Cotrimexazole dado el fracaso terapéutico al tratamiento inicial. (Tabla 5.)

\section{Tabla 5}

\section{Esquema antibióticos usados}

\begin{tabular}{lllr}
\hline Tratamiento inicial & $\begin{array}{c}\text { N. } \\
\text { de } \\
\text { casos }\end{array}$ & $\begin{array}{l}\text { Tratam. } \\
\text { definit. }\end{array}$ & $\begin{array}{c}\text { N. } \\
\text { de } \\
\text { casos }\end{array}$ \\
\hline 1. Cefalotina Amikacina & 3 & Id. & 3 \\
2. Cefalotina Cotrimezaxol & 3 & Id. & 20 \\
3. Ampicilina Cloxacilina & 8 & Id. & 0 \\
4. Penicilina Gentamicina & 6 & Id. & 0 \\
5. Ampicilina Gentamicina & 3 & Id. & 0 \\
\hline
\end{tabular}

La duración del tratamiento definitivo es de 25 dias.

La evolución de los 6 pacientes que reciben los dos primeros esquemas es satisfactoria a diferencia del resto ( 17 casos) que debido al fracaso terapéutico inicial es necesario modificar el esquema antibiótico al ya señalado. A pesar de lo cual fallecen en este grupo 5 casos (21.73\%), uno de ellos antes de las 48 horas, presentando el resto una evolución satisfactoria.

Grupo B: R.N.

El $100 \%$ de los R.N., son PreT. A.E.G. $y$ proceden de la Maternidad del Hospital Dr. Juan Noé, destacando que el $83,3 \%$ pesó menos de 2000 gramos al nacer. (Ver Tabla 6.)

\section{Tabla 6}

Distribución por peso de nacimiento

\begin{tabular}{lcc} 
Peso de nacimiento & $\begin{array}{c}\text { N.o de } \\
\text { casos }\end{array}$ & $\%$ \\
\hline $2000 \mathrm{~g}$ & 2 & 16,6 \\
$1500 \mathrm{~g}-2000 \mathrm{~g}$ & 8 & 66,6 \\
$1500 \mathrm{~g}$ & 2 & 16,6
\end{tabular}

Los motivos de ingreso en orden de frecuencia son prematurez $83,3 \%$ e infección ovular $41,6 \%$ siendo menos frecuentes Asfixia neonatal grave 25\%, Sindrome de dificultad respiratoria jdiopatico, Hemorragia intracraneana e Hipoglicemia ( $16 \%$ cada uno)

La demora diagnóstica oscila entre 2 y 11 días, destacando que en el $66,6 \%$ de los casos se realiza antes de los 4 días.

Los hallazgos clínicos pesquisados en un momento determinado de su evolución en orden de frecuencia son: distensión abdominal y rechazo alimenticio ( $100 \%$ ) Hepatoesplenomegalia $(75 \%)$ y el Síndrome de dificultad respiratoria $(58 \%)$. (Ver Tabla 7.)

Table 7

Manifestaciones clínicas en R.N. portadores de Sepsis a Klebsiella

\begin{tabular}{lrr}
\hline & $\begin{array}{c}\text { N. de } \\
\text { casos }\end{array}$ & \\
\hline Distensión abdominal & 12 & 100 \\
Rechazo alimenticio & 12 & 100 \\
Hepatoesplenomegalia & 9 & 75 \\
S.D.R. (Quejido, apnea, cianosis) & 7 & 58 \\
Ictericia & 6 & 50 \\
Escleredema & 6 & 50 \\
Fiebre & 2 & 16 \\
Diarrea Purulenta & 2 & 16 \\
Sínd. Purpúrico & 1 & 8 \\
\hline
\end{tabular}


Como en el grupo anterior, los exámenes de mayor utilidad diagnóstica son el Hemograma y los cultivos. En el primero encontramos desviación a izquierda (más de $15 \%$ de baciliformes) en un $75 \%$, seguido por leucocitosis (mayor de 20.000 leucocitos), trombopenia $y$ anemia hemolitica, cada uno de ellos con un 50\%. De los cultivos, encontramos Hemocultivos positivos en un $100 \%$, coprocultivo (+) en un $16 \%$ y ct livo de secreción umbilical (+) en un $8 \%$ destacando que el cultivo de L.C.R. es negativo en todos los casos.

En cuanto al tratamiento, éste se ínicia en 6 casos con Ampicilina-Cefalotina, dado el antecedente epidemiológico y cuadro clínico sugerente, previa toma de cultivos. En el resto se inició esquema habitual de Sepsis con Penicilina-Gentamicina. Posteriormente debido al fracaso terapéuticos, antecedentes epidemiologicos $y$ hallazgo de cultivos (+) a Klebsiella, se realiza cambio de esquema antibiótico, evolucionando 6 casos en forma satisfactoria y falleciendo el resto $(50 \%)$, uno de los cuales lo hace antes de las 48 horas. (Ver Tabla 8.)

\section{Tabla 8}

Tratamiento inicial

$N^{\circ}$ de Tratam. N. ${ }^{\circ}$ de casos definit. casos

1. Penicilina Gentamicina

2. Ampicilina Cefalotina

3. Cefalotina Amikacina

La duración del tratamiento fue de 25 a 35 días.

Dentro de las complicaciones en el grupo de Lactantes destacan una Hepatitis Séptica y una C.I.D. que fallecen. En los R.N. hay tres casos de Hepatitis Séptica, no observandose otras complicaciones.

\section{DISCUSION}

Un $89 \%$ de los casos se presentaron en forma epidérnica durante los meses de noviembre/78 y marzo/79. Cabe destacar que fue durante este período que nuestro Servicio se vio sobrepasado en su capacidad de hospitalización, presentándose en reiteradas oportunidades el hecho de tener 2 pacientes por cama, lo cual, es un factor predisponente a este tipo de infecciones.
En el estudio epidemiológico efectuado en el Servicio, encontramos cultivos (+) a Klebsiellas en la elaboración terminal de las mamaderas de Sedile, coincidiendo éstos con una falla mecánica en el proceso de esterilización, la cual posteriormente fue subsanada, negativizándose los cultivos en controles sucesivos. También ocurrió este hallazgo en un lavamanos de una de las salas de la Unidad de Lactantes. El estudio epidemiológico efectuado en el personal fue (-).

Cabe destacar que la cepa encontrada fue la misma de mamaderas, lavamanos y hemocultivos de los pacientes.

De la revisión de nuestros casos, destaca que el 52\% son lactantes menores de 6 meses, y un $65 \%$ presentó algún grado de déficit nutricional. (D.G.P. II y III 47,8\%), lo cual creemos favorece la incidencia de este cuadro, coincidiendo con los resultados de otras publicaciones nacionales. ${ }^{3,6}$

En el grupo de lactantes un $69,8 \%$ ingres 6 con diagnóstico clínico y radiológico de Neumopatías ag., (lo cual difiere con otros resultados nacionales), ${ }^{3,6}$ y dada la mala evolución clínica y radiológica fue necesario descartar un cuadro Séptico u otra complicación, confirmándose el diagnóstico de Sepsis por Klebsiella Pneumoniae en un $43 \%$ de los casos durante la primera semana de hospitalización. Atribuímos la mayor demora diagnóstica en el resto de los casos, a la negatividad de los cultivos en los primeros momentos y la no existencia de signos clínicos sugerentes. Además destaca la baja positividad de otros cultivos (orina, deposición, L.C.R., secreciones).

Hespecto al esquema terapéutico inicial éste fue múltiple debido a: 1) diagnóstico de ingreso y edad del paciente. 2) disponibilidad de medicamentos y 3) antibioticoterapia previa. Este fue modificado, una vez confirmado el diagnóstico y en algunos casos debido a una fuerte sospecha de él (previa toma de cultivos).

De acuerdo a la literatura, ${ }^{8 .}$. 10 y 11 el mejor antibiótico a usar en estos casos es la Amikacina, de la cual dispusimos a partir de Enero/79, pudiendo ser tratados con ello 3 lactantes, con éxito terapéutico. Es necesario recalcar, por los antecedentes señalados, que en los otros 20 casos se empleó el esquema Cefalotina Sódica más Cotrimexazol, con resultados similares.

$L_{\text {a letalidad en nuestra serie fue de } 21,73 \%}$ (lactantes), destacando que de los 5 fallecidos, 2 presentaban Sindrome de Down más Cardiopatia Congénita, 2 desnutrición grado III y el 5to. caso 
presentaba Bronconeurtonfa de evolución progresiva, falleciendo en insuficiencia respiratoria a pesar de estar conectado a respirador.

\section{Recién Nacido}

En el Servicio de Recién Nacido se presentó una situación similar al de Lactantes, produciéndose una alta demanda de incubadoras, sobrepasando con creces los recursos materiales y humanos del Servicio.

Como se mencions anteriormente el $100 \%$ de los casos son Prematuros, con alta frecuencia de R.P.M. $50 \%$ y parto distócico $(41 \%)$

En Recién Nacido el tratamiento especifico (Amikacina) se instaura precozmente debido al antecedente epidemiológico, cuadro clínico sugerente $\mathbf{y}$ factores de riesgo antes señalado. Además del tratamiento especifico se realiza recambio sanguíneo, en tres casos con malos resultados, falleciendo los tres.

Entre las complicaciones destaca señalar Hepatitis Séptica en tres casos, un caso H.I.C. No encontrándose compromiso meníngeo, ni articular en ningún caso de nuestras series.

Creemos que de no haber tomado las siguientes medidas epidemiológicas como cierre del Servicio de Pediatría y su desinfección completa, aislamiento de los casos confimados y contactos en lugares separados y asistencia Médica y de Enfermeria exclusiva, la magnitud del problema habría sido mayor.

\section{RESUMEN}

Se analiza la experiencia de 35 casos de Sepsis por Klebsiella Pneumoniae, ocurridos en el Servicio de Pediatría del Hospital Dr. Juan NoéC. de Arica entre los meses de noviembre/78 a octubre/79.
Veintitrés casos son Lactantes, de los cuales un $52 \%$ son menores de 6 meses y un $65 \%$ presenta algún grado de déficit nutricional. Doce son R.N. PrT, con P. Nacimiento: entre 1.000 y 2.300 $\mathrm{g}$, de los cuales un $50 \%$ tiene antecedentes de R.P.M. y un $41 \%$ parto distócico.

Los esquemas terapéuticos utilizados fueron Cefalotina más Cotrimexazol y Cefalotina más Amikacina, respectivamente.

La letalidad fue de 21,73 en Lactantes y $50 \%$ en los R. Nacidos.

\section{REFERENCIAS}

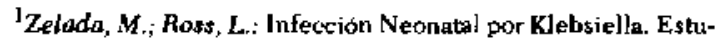
dio clínico y epidemiologico

${ }^{2}$ Herskovic, F.; Geidres, V.; Beca.J. P.; Howand, J,; Romdn, Cl. Septicemia por Klebsiella Enternbacter en Recién Nacidos. Rev. Ch. Ped. 50: 37-1979.

${ }^{3}$ Compbeil, M.; Puentes, R.; Talesnik, E.; Pruyas, M.; Taboadd, H.: Septicemias bacterianas en el lactante. Rev. Ch. Ped. 50. 5.1979.

${ }^{4}$ Herskovic, P.; Toso, A.; Beca,J. P.; Donoso, E.: Etiología de las infecciones bacterianas neonatales. Hev. Ch. Ped. 50: 43-1979.

5 Corrigan. J.: Thrombocytopenia: A laboratory sign of septicemia in infants and children.

${ }^{6}$ Zamorano, M.; Yañez, M.; Guerra, P.: Análisis clínico de 75 casos de Sepsis en el lactante del Servicio de Pediatria del Hospital Regional. Leonardo Guzmán de Antofagasta. Rev Ch. Ped. 50: 27-1979.

${ }^{7}$ Zipursky, A.; Palko, I, Milner, R.: The Hematology of Bacterial Infections in Premahure Infants. Pediatrics Vol. 57 N. ${ }^{\circ} 6$ June 1976. 839

${ }^{B}$ McHenry, M.; Fieker. D. O.: Newer Astibacterial and Antimycotic Drugs. Med. Clinics of North America. Vol. 62: 873 sept. 1978.

${ }^{9}$ Howard, J.; McCracken, G.; Trujillo, H.; Mohs, E.: Amikacin in Newborn Infants: Comparative Pharmacology with Kanamyein and Clinical Efficacy in $\mathbf{4 5}$ Neonates with Bacterial Diseases. Antimicrobial Agents and Chemotherapy. Aug. 1976, p. 205-210.

${ }^{10}$ Agbayani, M., Khan, A.; Ihaveri, $R$.: Antimicrobial Therapy in the Neonate.

${ }^{11}$ Eichenwald, $H_{\text {; }}$ MoCracken, G.: Antimicrobial Therapy in infants and children. The Journal of Pediatrics. Vol. $93 \mathrm{~N}{ }^{\circ}$ 3-337. Sep. 78 . 